5. Венгер, Л. А. «Игры и упражнения по развитию умственных способностей» / Л. А. Венгер. Москва, 2003. - 123 с.

6. Выготский, Л. С. Педагогическая психология / Л. С. Выготский; под редакцией В. В. Давыдова. Москва: Педагогика-Пресс, 1999. - 536 с.

7. Гальперин, П. Я. Введение в психологию: учебное пособие для вузов / П. Я. Гальперин. - Москва: Книжный дом «Университет», 1999. - 136 с

8. Гальперин, П. Я. Методы обучения и умственное развитие ребёнка / П. Я. Гальперин. - Москва, 1985. $-185 \mathrm{c}$.

9. Давыдов, В. В. Психологическая теория учебной деятельности и методов начального обучения, основанных на содержательном обобщении / В. В. Давыдов. - Томск: Пеленг, 1992. - 136 с.

10. Данилов, М. А. Вопросы воспитания познавательной активности и самостоятельности школьников / М. А. Данилов. - Казань, 1979. - 158 с.

11. Данилов, М. А. Логика учебного процесса / М. А. Данилов // Вопросы повышения эффективности урока / Московский педагогический государственный университет имени Ленина. - Москва, 1959. $-285 \mathrm{c}$.

12. Дейкина, А. Ю. Познавательный интерес: сущность и проблемы изучения / А. Ю. Дейкина. Москва: Просвещение, 2002. -235 с.

13. Додонов, Б. И. О сущности интересов и подход к их исследованию / Б. И. Додонов // Советская педагогика. - 1971. - № 9. - С. 72-82.

14. Зотов, Ю. Б. Организация современного урока: книга для учителя / Ю. Б. Зотов; под редакцией П. И. Пидкасистого. - Москва: Просвещение, 1987. - 144 с.

15. Казанцева, И. Н. Урок в школе / И. Н. Казанцева. - Москва, 1956. - 106 с.

16. Морозова, Н. Г. Учителю о познавательном интересе / Н. Г. Морозова. - Москва: Знание, 1979. $450 \mathrm{c}$.

17. Немцева, Ю. С. Развитие познавательного интереса школьников 7-9 классов средствам чертёжной графики: канд. пед. наук: 13.00.01 / Ю. С. Немцова. - Магнитогорск, 2006. - 198 с.

18. Педагогический энциклопедический словарь / М. М. Безруких, В. А. Болотов, Л. С. Глебова [и др.]. - Москва: Большая Российская энциклопедия, 2003. - 528 с.

19. Трубинова, К. М. Познавательный интерес и его развитие в процессе обучения в начальной школе / К. М. Трубинова. - Текст: электронный // Педагогика сегодня: проблемы и решения: материалы II Международной научной конференции (г. Казань, сентябрь 2017 г.). - Казань: Молодой ученый, 2017. - C. 9-14. - URL: https://moluch.ru/conf/ped/archive/270/12881/ (дата обращения: 06.02.2021).

\title{
Дурягина Е.Г. \\ Роль эксперимента при изучении химии студентами естественнонаучного направления
}

Российский Государственный Гидрометеорологический Университет (Россия, Санкт-Петербург)

doi: $10.18411 / \mathrm{j}-06-2021-170$

\section{Аннотация}

В данной статье показано значение эксперимента, при изучении химии студентами естественнонаучного направления, перечислены различные виды эксперимента.

Ключевые слова: химия, эксперимент, опыт, лабораторная работа, естественнонаучное направление.

\section{Abstract}

The article describes meaning of experiment for students of natural-scientific area and itemizes different types of experiment.

Keywords: chemistry, experiment, test, laboratory work, natural-scientific area.

«Призывая к теоретическим химическим занятиям, я убежден, что зову людей к полезнейшему труду... А для этого необходимо усвоить прежде всего химическую практику, т.е. мастерство предмета, искусство спрашивать природу и слышать ее 
ответы в лабораториях и книгах.» Д.И. Менделеев, «Основы химии», из предисловия к 4-му изданию.

Основной целью, при освоении студентами естественнонаучных дисциплин, является формирование у них научной картины мира, освоение современных технологий и методов познания окружающей среды. Знание основных законов природы, позволяет рациональнее использовать их в интересах общества, способствует формированию материалистического мировоззрения.

Среди дисциплин, составляющих базовую подготовку специалистов естественнонаучного направления, важное место занимает химия, которая является одной из естественных наук, изучающей состав, строение, свойства, превращения веществ и формы движения материи, а также окружающий нас материальный мир во всем многообразии его форм и превращений. Знание химии необходимо для понимания основных процессов, ответственных за формирование химического состава атмосферы и гидросферы, факторов, влияющих на изменчивость их химического состава, для защиты и сохранения здоровья людей.

Цель дисциплины состоит в формировании у студентов комплекса научных знаний о химических веществах и процессах их превращений, при которых происходит изменение состава и структуры. При этом должно быть обеспечено глубокое понимание сущности химических взаимодействий, имеющих место в природе и определяющих химическую форму движения материи. Студенты должны уметь применять эти знания для решения практических и научных задач.

Согласно рабочим программам, при обучении химии в высших учебных заведениях, выделяются четыре основные формы организации обучения: лекции, практические занятия, лабораторные занятия, самостоятельная работа.

Во время лабораторных занятий студенты обучаются навыкам экспериментальной работы, умением обращаться с приборами, самостоятельно делать выводы из полученных данных. Особенно большое значение имеет обучение навыкам экспериментальной работы для студентов естественнонаучного направления. Эксперимент - это основа изучения химии. Без его использования невозможно познать этот предмет.

Обучение студентов естественно-научного направления включает в себя лабораторные работы по таким предметам, как химия и физика. Лабораторную работу можно выполнить по большинству тем из рабочей программы по химии. Закрепление теории экспериментом оптимизирует результат. Учебный эксперимент кроме привития умения и навыков работы в химической лаборатории, кроме закрепления и лучшего усвоения учебного материала учит наблюдать, добиваться самостоятельного объяснения наблюдаемых процессов и делать выводы из проводимых опытов, учит мыслить. Химический эксперимент - важный источник знаний. В сочетании с техническими средствами обучения он способствует более эффективному овладению знаниями, умениями и навыками. Систематическое использование на уроках химии эксперимента помогает развивать умения наблюдать явления и объяснять их сущность в свете изученных теорий и законов, формирует и совершенствует экспериментальные умения и навыки, прививает навыки планирования своей работы и осуществления самоконтроля, воспитывает аккуратность, уважение и любовь к труду. Химический эксперимент способствует общему воспитанию и всестороннему развитию личности [1].

Различают научный и учебный эксперимент, демонстрационный эксперимент.

Учебный эксперимент отличается от научного тем, что результаты его известны, условия его проведения подобраны так, что в процессе проведения опытов или их наблюдения учащиеся должны обнаружить известные признаки реакции и прийти к ожидаемым результатам. Эксперимент и связанные с ним наблюдения необходимы уже при изучении первоначальных химических понятий. Их роль возрастает при изучении 
теоретических вопросов химии, при определении свойств простых веществ и соединений элементов периодической системы, важнейших классов органических веществ, а также при выявлении генетической связи важнейших классов неорганических и органических веществ [2].

Демонстрационный эксперимент выполняет в основном преподаватель при изложении нового материала. Он позволяет сделать понятными важные выводы, учит выполнять лабораторные опыты и отдельные операции и приемы. Но он не вырабатывает необходимые экспериментальные умения и навыки, поэтому должен дополняться экспериментами, проводимыми студентами самостоятельно.

В учебном химическом эксперименте наиболее общими являются следующие компоненты:

1) изучение химических объектов (веществ и химических реакций), рассчитанное на одновременное восприятие всеми обучаемыми;

2) постановка целей и задач эксперимента;

3) экспериментальная деятельность самих обучаемых;

4) освоение техники химического эксперимента.

На основе этих общих компонентов понятие учебный химический эксперимент можно представить как специальным образом организованный фрагмент процесса обучения, направленный на познание объектов химии и развитие экспериментальной деятельности обучаемых.

Эксперимент - это один из основных способов постигнуть основы науки. Результаты эксперимента, получаемые студентами, стимулируют их мышление, приводят к обсуждению, заставляют делать выводы. Все это в совокупности оптимизирует процесс обучения. Использование очень простых инструментов зачастую оказывает помощь в обучении, упрощая процесс усвоения материала [3].

Академик С. И. Вавилов указывал на двойную роль эксперимента: 1) эксперимент доказывает или отвергает какие-либо теоретические положения; 2) эксперимент может стать предпосылкой новой теории или гипотезы, которая должна быть подтверждена новыми экспериментами. Обе стороны эксперимента неразрывно связаны. «Ответ, даваемый опытом, - подчеркивал он, - иногда может быть неожиданным, и тогда опыт становится первоисточником новой теории. Так, например, возникло учение о радиоактивности. В этом самое ценное, эвристическое значение опыта». «Развитие познания, - отмечал известный советский философ П. В. Копнин, предполагает непрерывное взаимодействие опыта, в частности эксперимента, и теоретического мышления...».

Систематическое использование эксперимента на занятиях по химии помогает бороться с формализмом знаний, развивает умение наблюдать факты и явления и объяснять их сущность в свете изучения теорий и законов.Так же химический эксперимент - практические работы - позволяют применять знания, умения и навыки учащихся, контролировать эффективность учебного процесса и его качество.

Лабораторные занятия являются одним из видов химического эксперимента, применяемого при совершенствовании и закреплении знаний. В процессе проведения занятий студенты глубже и полнее вникают в химические явления и законы, овладевают техникой и изучением свойств веществ.

Лабораторные опыты - это эксперимент, который выполняют учащиеся под непосредственным руководством учителя. Лабораторные опыты являются, как правило, единичными и помогают изучить отдельные стороны химического объекта.

Лабораторные работы представляют собой совокупность лабораторных опытов и позволяют изучить многие стороны химических объектов и процессов. Лабораторные работы заключаются в проведении учащимися по заданию учителя опытов с использованием приборов, инструментов и прочего оборудования. По времени они могут занимать от 5-10 до 40-45 мин (лабораторный урок). На лабораторном уроке учащиеся работают в основном не по заданиям и не по книге, а на основании живого слова преподавателя [4]. 
Цель лабораторных опытов - приобретение новых знаний, изучение нового материала.

С помощью реального опыта можно расширить кругозор, получить различные практические навыки, наконец, просто, понять и запомнить «скучные» правила и законы. Именно эксперимент - источник знания о химических веществах и их превращениях, позволяющий увлечь учащихся химической наукой, развивающий способность применять теоретические знания на практике. Только опытным путем можно подтвердить или опровергнуть гипотезу, возникшую при наблюдении [5].

Быть уверенным в точности, поставленного эксперимента, можно только при знании техники лабораторных работ. Так, при аналитических исследованиях имеет очень большое значение чистота химической посуды; так как могут быть получены искаженные результаты опыта и сделаны неправильные выводы при использовании недостаточно чисто вымытой химической посуды.

Значение техники лабораторных работ в настоящее время выросло так, что она стала превращаться в самостоятельный раздел общехимической подготовки. В некоторых высших учебных заведениях отводится специальное время на изучение этого предмета.

Техника лабораторных работ основана на строгих научных принципах; в настоящее время она имеет большое прикладное значение. Правильное проведение любой операции в лабораторной работе возможно только в том случае, если исполнитель понимает их смысл и смысл тех теоретических предпосылок, которые лежат в их основе. Это значит, что для того, чтобы овладеть техникой лабораторных работ, необходимо знать теоретические основы химии, физики и смежных с ними наук.

Несмотря на то, что перед разными лабораториями стоят разные цели, все они имеют много общего в отношении организации, оборудования и характера основных лабораторных работ.

Основным оборудованием учебной химической лаборатории является рабочий стол, на котором проводится вся экспериментальная работа. Также необходимы водопровод, канализация, наличие электрических розеток. В каждой лаборатории должен быть вытяжной шкаф, должны иметься установки для дистилляции воды, емкости для сливания ненужных реактивов. Должны быть в наличии необходимые справочники, учебники и пособия.

При работе в лаборатории следует обращать внимание на создание такой обстановки, которая бы облегчала работу. Искусство химика состоит в том, чтобы получить нужные результаты с помощью самых обыкновенных средств и аппаратуры.

Необходимо стремиться к рационализации работы, стараясь получить максимальный эффект при минимальной затрате средств, времени и труда. Важнейшими условиями для достижения этого являются: 1) целесообразное устройство лаборатории; 2) подбор соответствующих инструментов, посуды и необходимых аппаратов и 3) экономное использование материалов при постановке экспериментов.

Последнее достигается проведение опытов с небольшим количеством вещества. При этом отдельные операции (нагревание, охлаждение, фильтрование, высушивание, перегонка и т.д.) требуют несравненно меньше труда и времени, давая одинаковый конечный результат с результатом опыта, проведенного в большем масштабе [6].

Лабораторная работа - явление многофункциональное. Основными целями лабораторных работ являются: апробация и закрепление знаний, полученных при изучении теоретического материала; повышение способности к рассуждению, к научному мышлению; пробуждение интереса к эмпирическим знаниям; оптимальная передача знаний; обучение путем эффективных и активных действий; моделирование использования инновационных методов производств и технологий; доказательство на практике того, что студенты получили из учебников; обеспечение более глубокого понимания предмета; создание чувства сотрудничества.

Студенты, не получившие навыков практического применения полученных во время учебы знаний, не смогут применить их в производственной деятельности. Только 
при выполнении лабораторных работ, можно приобрести те навыки, которые помогают использовать теоретические знания. Благодаря проведению различных экспериментов, легче уяснить различные понятия химии, объяснить те или иные явления.

Умение применять знания при выполнении химического эксперимента можно считать сформированным, если студент может правильно провести опыты, предусмотренные программой, самостоятельно осуществить необходимые наблюдения, достичь поставленной цели и сделать выводы, если он соблюдает правила поведения в лаборатории, не нарушает технику безопасности, а при проведении эксперимента не нуждается в помощи.

Любое знание без эксперимента - формальное знание. На теоретическом уровне достигается высший синтез знаний в форме научной теории. Основоположник отечественной науки М. В. Ломоносов отмечал: «Опыт ценнее тысячи мнений, рожденных воображением», а академик Л. Д. Ландау говорил: «Опыт - верховный судья теории».

Эксперимент позволяет установить причинно-следственные связи между явлениями. Он позволяет выяснить кинетику, динамику процессов и их энергетическую сущность.

Химический эксперимент придает особую специфику предмету химии. Он является важнейшим способом осуществления связи теории с практикой путем превращения знаний в убеждения.

Эксперимент - важнейший путь осуществления связи теории с практикой при обучении химии, превращения знаний в убеждения [7].

$$
* * *
$$

1. Ермаханов М.Н., Журхабаева Л.А., Адырбекова Г.М., Асылбекова Г.Т., Сабденова У.О., КуандЫкова Э.Т. ХИМИЧЕСКИЙ ЭКСПЕРИМЕНТ И ЕГО РОЛЬ В МЕТОДИКЕ ОБУЧЕНИЯ ХИМИИ // Международный журнал прикладных и фундаментальных исследований. - 2016. - № 13. - C. 398-399;

2. Атоев Э.Х. Химический эксперимент как важный аспект преподавания химии в академических лицеях и профессиональных колледжах / Э.Х. Атоев, М.Х. Холлиева, М.Р.Кувончева.- Текст: непосредственный // Молодой ученый.- 2015.- №3 (83).- C.727-728.- URL: https://moluch.ru/archive/83/15165/ (дата обращения : 11.12.2020).

3. Роль лаборатории для обучения химии, автор Ардистони Марям Сироджиен, рубрика Педагогика. Опубликовано в Молодой ученый №2 (49) февраль 2013г.

4. Верховский В.Н., Смирнов А.Д. Техника химического эксперимента. Т. 1. М., 1973;

5. Бахтиярова Ю.В., Миннуллин Р.Р., Галкин В.И. Основы химического эксперимента и занимательные опыты по химии: учебное пособие для вузов и школ / Ю.В. Бахтиярова, Р.Р. Миннуллин, В.И. Галкин. - Казань: Изд-во Казан. ун-та, 2014. - 144 с.

6. Воскресенский П.И. Техника лабораторных работ, М., Изд-во «Химия», 1973, С.717.

7. Амирова А.Х. Демонстрационный и ученический эксперимент в практике обучения химии // Химия в школе. 2004. - №6. - С. $62-66$.

\section{Ивашов О.А.}

\section{Современные проблемы обучения иностранному языку спортсменов-} профессионалов

ФГАОУ ВО «Северо-Кавказский федеральный университет» (Россия, Ставрополь)

\section{Аннотация}

В статье рассматриваются современные проблемы обучения иностранному языку спортсменов-профессионалов и предлагаются пути повышения эффективности обучения.

Ключевые слова: коммуникативная компетенция, иноязычная коммуникация, профессиональное общение. 